Proceeding Paper

\title{
Investigation of Acridinedione Derivative Synthesis with Versatile Morphologies of $\mathrm{Bi}_{2} \mathrm{O}_{3}$ Nanoparticles ${ }^{\dagger}$
}

\author{
Hossein Ghafuri *, Bahareh Pourakbari, Peyman Hanifehnejad and Zeinab Tajik
}

\footnotetext{
Citation: Lastname, F.; Lastname, F.; Lastname, F. Investigation of Acridinedione Derivatives Synthesis with Versatile Morphologies of $\mathrm{Bi}_{2} \mathrm{O}_{3}$ Nanoparticles. Chem. Proc. 2021, 3, 118. https://doi.org/10.3390/10.3390/ ecsoc-24-08327
}

Academic Editors: Julio A. Seijas and M. Pilar Vázquez-Tato

Published: 14 November 2020

Publisher's Note: MDPI stays neutral with regard to jurisdictional claims in published maps and institutional affiliations.

Copyright: $\odot 2020$ by the authors. Licensee MDPI, Basel, Switzerland. This article is an open access article distributed under the terms and conditions of the Creative Commons Attribution (CC BY) license (http://creativecommons.org/licenses/by/4.0/).

\author{
Catalysts and Organic Synthesis Research Laboratory, Department of Chemistry, Iran University of Science \\ and Technology, Tehran 16846-13114, Iran; bahareh_pourakbari@chem.iust.ac.ir (B.P.); \\ p_hanifehnejad@chem.iust.ac.ir (P.H.); z_tajik@chem.iust.ac.ir (Z.T.) \\ * Correspondence: ghafuri@iust.ac.ir \\ + Presented at the 24th International Electronic Conference on Synthetic Organic Chemistry, \\ 15 November-15 December 2020; Available online: https://ecsoc-24.sciforum.net/.
}

\begin{abstract}
In this study, $\mathrm{Bi}_{2} \mathrm{O}_{3}$ nanoparticles were successfully synthesized through a facile hydrothermal procedure. The structure of the $\mathrm{Bi}_{2} \mathrm{O}_{3}$ nanoparticles was analyzed by Fourier transfer infrared spectroscopy (FTIR) and scanning electron microscopy (SEM). The synthesized $\mathrm{Bi}_{2} \mathrm{O}_{3}$ nanoparticles have unique properties, such as high activity, high purity, and high surface area. Hence, we have reported the $\mathrm{Bi}_{2} \mathrm{O}_{3}$ nanoparticles as an efficient, cost-effective, and mild catalyst for the synthesis of acridinedione derivatives via a one-pot four-component reaction. In addition, the effect of the morphology of the $\mathrm{Bi}_{2} \mathrm{O}_{3}$ nanostructure was investigated on catalytic performance. Therefore, $\mathrm{Bi}_{2} \mathrm{O}_{3}$ nanoparticles were prepared and applied as a heterogeneous catalyst in the synthesis of acridinedione derivatives. The present approach offers several advantages, such as excellent yields within short times, green catalyst, and ease of recovery.
\end{abstract}

Keywords: $\mathrm{Bi}_{2} \mathrm{O}_{3}$ nanoparticles; acridinedione derivatives; organic synthesis

\section{Introduction}

Nowadays, scientists are using multicomponent reactions to synthesis complex organic compounds due to their high efficiency. These reactions have attracted sizeable attention due to their many applications in various fields, such as medicine, agriculture, and intermediates [1]. The different multicomponent reactions, like Mannich, Biginelli, Strecker, Hantzsch, and acridinedione derivative synthesis, are significant organic transformations for the synthesis of pharmaceutical compounds [2]. Acridinedione compounds are a class of heterocyclic compounds due to their unique properties, such as anticancer, antimicrobial, antibacterial, and their fluorescence properties, their use in various fields, including pharmaceutical, biological, and laser dyes. Different methods have been used to synthesize acridinedione derivatives, which usually suffer from hazard solvents, expensive reagents, and high reaction times. Heterogeneous catalysts have a crucial role in determining the conditions of reactions $[3,4]$. They are known as compounds or substances that speed up a chemical reaction without changing it. The advantages of heterogeneous catalysts are high activity, high surface area, long lifetimes, thermal stability, selectivity, and non-toxicity [5].

As mentioned, the acridinedione derivatives are one of the attractive reactions in chemistry that have been synthesized with various catalysts, such as nano-ferrite, $\mathrm{TiO}_{2}$ carbon nanotube, $\mathrm{SiO}_{2}$, $\mathrm{Rh}$ (III), and Amberlyst-15. In addition, bismuth oxides have shown excellent catalytic properties. They have potential applications in solar cells, gas sensors, and piezoelectric-optical materials. The other attractive features of bismuth oxides included non-toxicity, ionic conductivity, a high refractive index, and remarkable conductivity, making it possible for them to be used as efficient catalysts to promote the 
synthesis of acridinedione derivatives [6]. Besides these properties, the various morphologies of $\mathrm{Bi}_{2} \mathrm{O}_{3}$ nanoparticles, including nanowire, nanotube, nanoflake, nanofiber, and nanobelt, have been successfully synthesized. The synthesis of bismuth oxide nanoparticles has been reported with various protocols such as sol-gel, hydrothermal, and precipitated. These nanoparticles have extraordinary properties, such as high activity, high purity, and high surface area [7].

In this paper, we report the synthesis of $\mathrm{Bi}_{2} \mathrm{O}_{3}$ nanoparticles as a heterogeneous recyclable catalyst for the preparation of acridinedione derivatives through four multicomponent condensation reactions, as shown in Scheme 1.

ArCHO

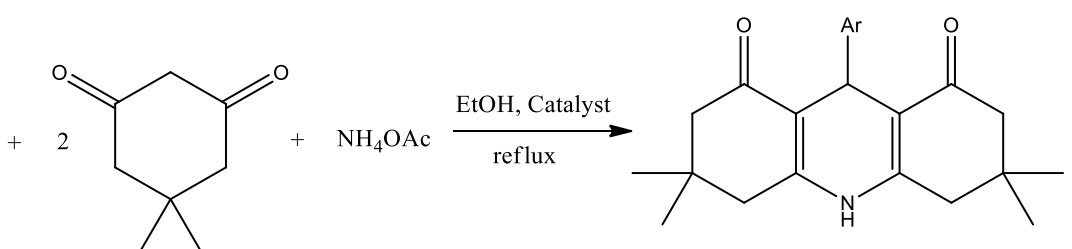

Scheme 1. Synthesis of acridinedione derivatives catalyzed by $\mathrm{Bi}_{2} \mathrm{O}_{3}$ nanoparticles.

\section{Experimental}

\subsection{General}

All reagents were purchased from the Fluka and Merck companies and used without further purification. Thin-layer chromatography (TLC) was used for the purity determination of substrates, products, and reaction monitoring over a silica gel 60 F254 aluminum sheet. Melting points were measured in open capillary tubes with an Electrothermal 9100 melting point apparatus. The FTIR spectra were measured with a Shimadzu IR-100 spectrometer. A MIRA3 TESCAN-XMU was used for FE-SEM images.

\subsection{Preparation of $\mathrm{Bi}_{2} \mathrm{O}_{3}$ Nanoparticles:}

\subsubsection{Method (A)}

We added $20 \mathrm{mg}$ of $\mathrm{Bi}_{2} \mathrm{O}_{3}$ to $100 \mathrm{~mL}$ of $\mathrm{H}_{2} \mathrm{O}$ and raised the $\mathrm{pH}$ to 11 using a $1.0 \mathrm{M}$ $\mathrm{NaOH}$ solution. While increasing the $\mathrm{pH}$, a white powder was obtained. The powder was filtered and washed with water and acetone. After drying the powder in an oven at $50^{\circ} \mathrm{C}$, it was calcined at $400{ }^{\circ} \mathrm{C}$ at the rate of $10{ }^{\circ} \mathrm{C} / \mathrm{min}$ and remained there for $30 \mathrm{~min}$. After calcination, a yellow powder was obtained.

\subsubsection{Method (B)}

We added $20 \mathrm{mg}$ of $\mathrm{Bi}_{2} \mathrm{O}_{3}$ to a solution of $40 \mathrm{~mL}$ of $\mathrm{H}_{2} \mathrm{O}$ and $40 \mathrm{~mL}$ of ethanol and raised the $\mathrm{pH}$ to 11 using a $1.0 \mathrm{M} \mathrm{NaOH}$ solution. After a few hours of vigorous stirring, the solution was poured into a Teflon-lined stainless autoclave and heated at $180{ }^{\circ} \mathrm{C}$ for $24 \mathrm{~h}$. Then the products were filtered and washed with water and acetone, and then dried at $80^{\circ} \mathrm{C}$ and a white powder was obtained.

\subsection{General Procedure for the Preparation of Acridinediones Derivatives}

We mixed $1.0 \mathrm{mmol}$ of ammonium acetate, $2.0 \mathrm{mmol}$ of dimedone, $1.0 \mathrm{mmol}$ of aromatic aldehyde, $3.0 \mathrm{~mL}$ of ethanol as a solvent, and $20.0 \mathrm{mg}$ of $\mathrm{Bi}_{2} \mathrm{O}_{3}$ nanoparticle as a catalyst in a round bottom flask. They were stirred in reflux conditions for an appropriate time. After completing the reaction (monitored by TLC), the reaction mixture was filtered and recrystallized by ethanol to afford the pure product.

\subsection{Spectral Data}

3,3,6,6-tetramethyl-9-phenyl-3,4,6,7,9,10-hexahydroacridine-1,8(2H,5H)-dione (1a): mp: $274-276{ }^{\circ} \mathrm{C}$, IR $\left(\mathrm{KBr}: v / \mathrm{cm}^{-1}\right): 3278,3213,2964,1636,1603,1477,1366,1251,1165$ [8]. 
3,3,6,6-Tetramethyl-9-(4-chlorophenyl)-3,4,6,7,9,10-hexahydroacridine-1,8(2H,5H)dione (2a): $\mathrm{mp}$ : $297-299^{\circ} \mathrm{C}$, IR (KBr: v/cm$\left.{ }^{-1}\right): 2976,2902,1648,1606,1490,1366,1220,1149$ [8].

3,3,6,6-Tetramethyl-9-(2,4-dimethoxyphenyl)-1,2,3,4,5,6,7,8,9,10-decahydroacridine1,8-dione (3a): mp: $265-267^{\circ} \mathrm{C}$, IR (KBr: v/ $\left.\mathrm{cm}^{-1}\right)$ : 3190, 3065, 2954, 1636, 1602, 1480, 1395, $1363,1292,1261,1217,1144,1124,1041,928,825$ [9].

9-(4-hydroxyphenol)-3,3,6,6-tetramethyl-3,4,6,7,9,10-hexahydroacridine-1,8(2H,5H)dione (4a): $\mathrm{mp}: 272-274{ }^{\circ} \mathrm{C}$, IR (KBr: v/cm-1): 3273, 2963, 1645, 1394 [10].

3,3,6,6-Tetramethyl-9-(3-nitrophenyl)-3,4,6,7,9,10-hexahydroacridine-1,8(2H,5H)-dione (5a): mp: $296-298{ }^{\circ} \mathrm{C}$, IR (KBr: v/cm-1): 3273, 3185, 3064, 2959, 1646, 1601, 1525, 1345 [11].

9-(4-nitrophenol)-3,3,6,6-tetramethyl-3,4,6,7,9,10-hexahydroacridine-1,8(2H,5H)-dione (6a): mp: $272-274{ }^{\circ} \mathrm{C}$, IR (KBr: v/ $\left.\mathrm{cm}^{-1}\right)$ : 3192, 2961, 1637, 1597 [10].

\section{Results and Discussion}

FE-SEM images and FTIR spectrum were used for the characterization of the $\mathrm{Bi}_{2} \mathrm{O}_{3}$ nanoparticles. In Figure 1, the FTIR spectrum, in the range of $400-4000 \mathrm{~cm}^{-1}$ to investigate the chemical bonding of the $\mathrm{Bi}_{2} \mathrm{O}_{3}$ nanoparticles, is shown. The 558 and $446 \mathrm{~cm}^{-1}$ peaks are related to $\mathrm{Bi}-\mathrm{O}$ stretching vibration modes, the $2364 \mathrm{~cm}^{-1}$ peak is related to the $\mathrm{CO}_{2}$ of the instrument, and the rest of the FTIR transmittance looks flat. The flat FTIR transmittance is evidence of the complete preparation of the $\mathrm{Bi}_{2} \mathrm{O}_{3}$ nanoparticles [12].

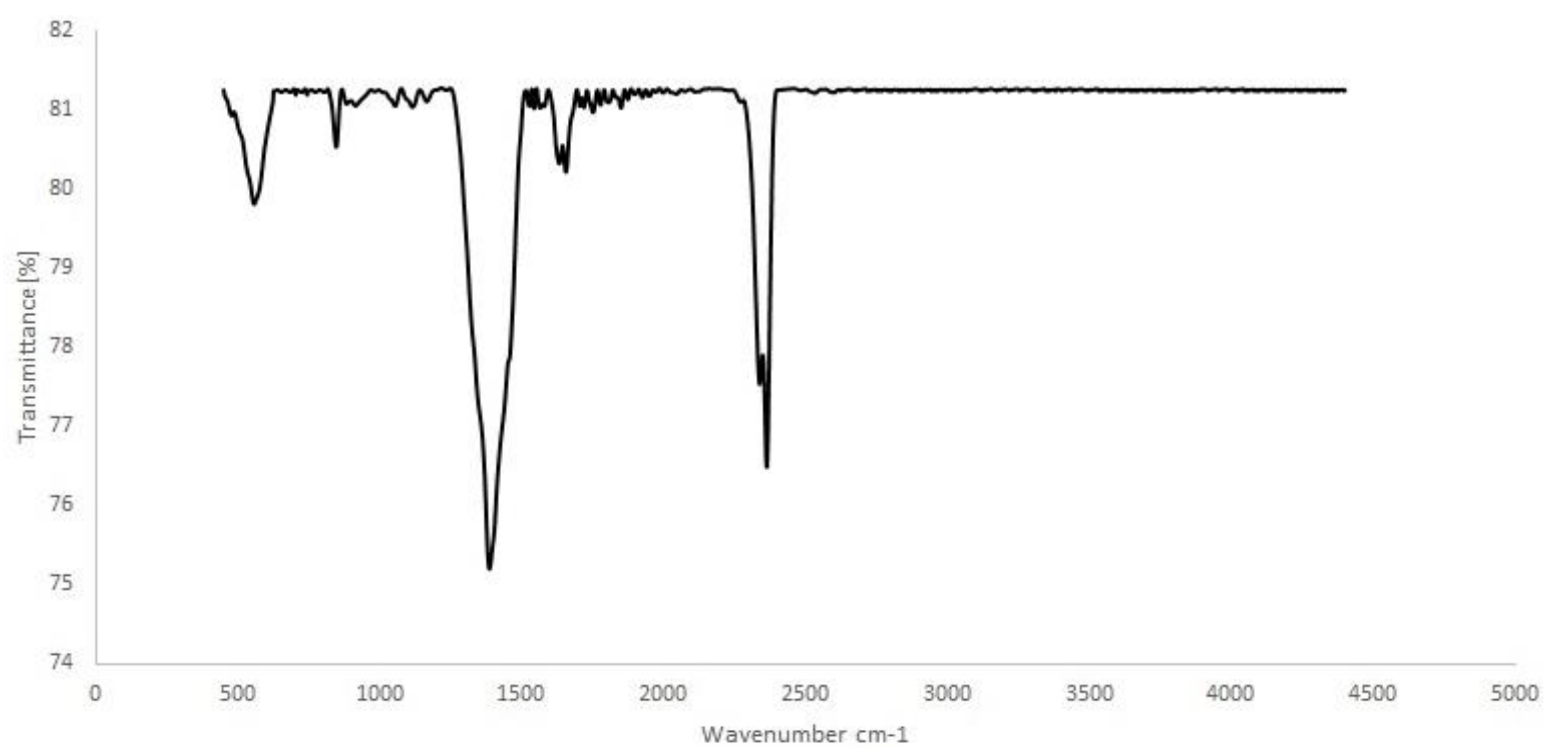

Figure 1. The FTIR spectra of $\mathrm{Bi}_{2} \mathrm{O}_{3}$ nanoparticles.

The morphology of the synthesized $\mathrm{Bi}_{2} \mathrm{O}_{3}$ nanoparticles was investigated using FESEM and is shown in Figure 2.

We applied $\mathrm{Bi}_{2} \mathrm{O}_{3}$ nanoparticles as a catalyst in the synthesis of acridinedione derivatives through multicomponent reactions to indicate the $\mathrm{Bi}_{2} \mathrm{O}_{3}$ nanoparticles' merits in organic synthesis. For this, we used six different aromatic aldehydes in optimum conditions, and the intended products were obtained in excellent yields. The results are shown in Table 1.

As shown in Table 1 , in comparison with method (B), the $\mathrm{Bi}_{2} \mathrm{O}_{3}$ nanoparticles synthesized by method (A) have more yield for acridinedione derivative synthesis. This result indicates that the morphology of $\mathrm{Bi}_{2} \mathrm{O}_{3}$ nanoparticles is one of the important agents for catalytic activity. 


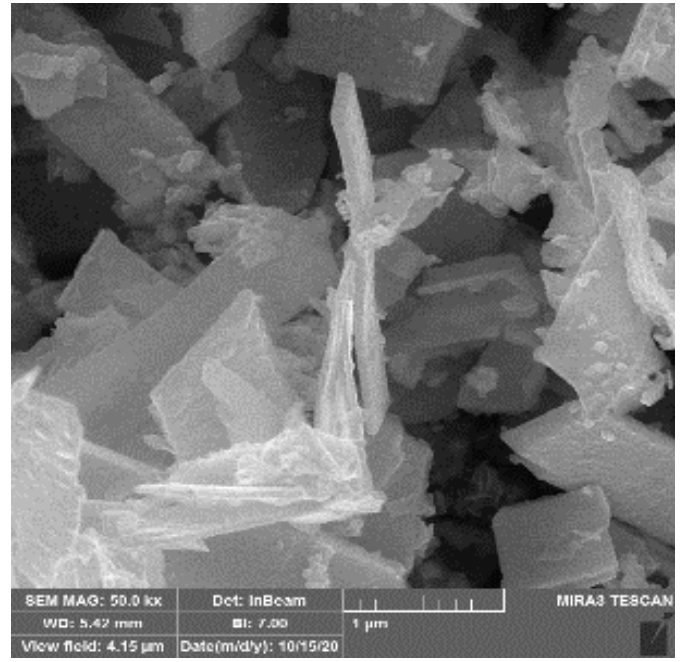

(a)

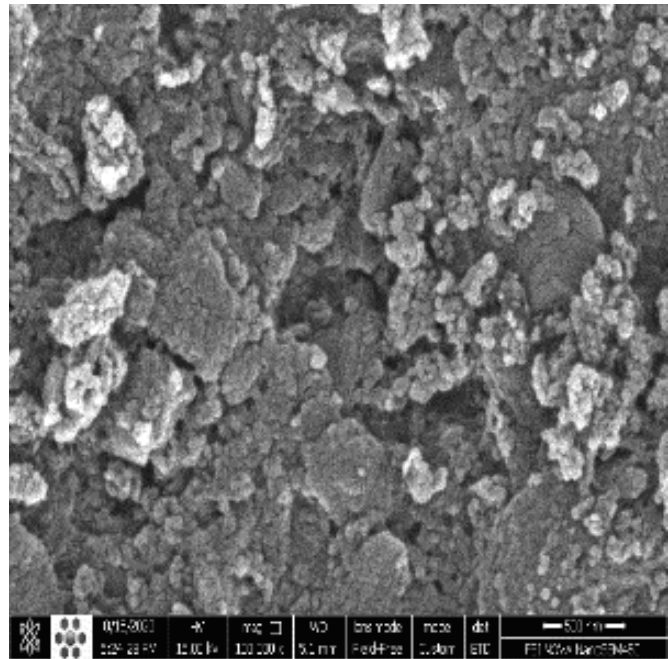

(b)

Figure 2. The FE-SEM images of $\mathrm{Bi}_{2} \mathrm{O}_{3}$ nanoparticles. (a) Method $\mathrm{A}(1 \mu \mathrm{m})(\mathbf{b})$ Method $\mathrm{B}(500 \mathrm{~nm})$.

Table 1. Synthesis of acridinedione derivatives catalyzed by $\mathrm{Bi}_{2} \mathrm{O}_{3}$ nanoparticles.

\begin{tabular}{|c|c|c|c|c|}
\hline Entry & Product & Time (min) & $\begin{array}{l}\text { Yield (\%) } \\
\text { Method A } \\
\text { Method B }\end{array}$ & $\mathrm{Mp}^{\circ} \mathrm{C}$ (Ref.) \\
\hline 1a & & 10 & $\begin{array}{l}92 \\
88\end{array}$ & $274-276[13]$ \\
\hline $2 a$ & & 12 & $\begin{array}{l}86 \\
80\end{array}$ & 297-299 [13] \\
\hline $3 a$ & & 18 & $\begin{array}{l}88 \\
82\end{array}$ & 265-267 [9] \\
\hline $4 a$ & & 15 & $\begin{array}{l}90 \\
82\end{array}$ & $272-274[14]$ \\
\hline $5 a$ & & 10 & $\begin{array}{l}88 \\
83\end{array}$ & 296-298 [13] \\
\hline
\end{tabular}


$6 a$

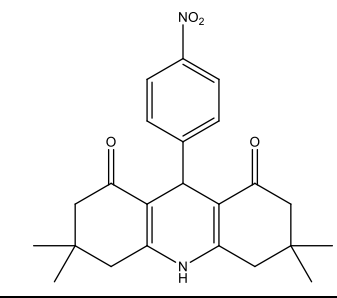

90

85

$272-274[13]$

\section{Conclusions}

We synthesized two different morphologies of $\mathrm{Bi}_{2} \mathrm{O}_{3}$ nanoparticles and used them as a catalyst in organic reactions and acridinedione derivative synthesis. A short reaction time, high yield, use of non-toxic solvent, and a mild condition reaction are the advantages of using $\mathrm{Bi}_{2} \mathrm{O}_{3}$ nanoparticles. The comparison of the results from the two morphologies demonstrates that the catalyst's morphology is among the most critical catalytic activity agents.

Funding: This research received no external funding.

Conflicts of Interest: The authors declare no conflict of interest.

\section{References}

1. Das, D. Multicomponent Reactions in Organic Synthesis Using Copper-Based Nanocatalysts. ChemistrySelect 2016, 1, 1959-1980.

2. Domling, A.; Wang, W.; Wang, K. Chemistry and biology of multicomponent reactions. Chem. Rev. 2012, 112, $3083-3135$.

3. Su, Q.; Li, P.; He, M.; Wu, Q.; Ye, L.; Mu, Y. Facile synthesis of acridine derivatives by $\mathrm{ZnCl}_{2}$-promoted intramolecular cyclization of o-arylaminophenyl Schiff bases. Org. Lett. 2014, 16, 18-21.

4. Gensicka-Kowalewska, M.; Cholewiński, G.; Dzierzbicka, K. Recent developments in the synthesis and biological activity of acridine/acridone analogues. RSC Adv. 2017, 7, 15776-15804.

5. Ramos, L.P.; Cordeiro, C.S.; Cesar-Oliveira, M.A.F.; Wypych, F.; Nakagaki, S. Applications of heterogeneous catalysts in the production of biodiesel by esterification and transesterification. In Bioenergy Research: Advances and Applications; Elsevier: Amsterdam, The Netherlands, 2014; pp. 255-276.

6. Li, W. Facile synthesis of monodisperse Bi2O3 nanoparticles. Mater. Chem. Phys. 2006, 99, 174-180.

7. Zhang, X.B.; Zhang, L.; Hu, J.S.; Huang, X.H. Facile hydrothermal synthesis and improved photocatalytic activities of Zn2+ doped Bi2MoO6 nanosheets. RSC Adv. 2016, 6, 32349-32357.

8. Eyvazzadeh-Keihan, R.; Bahrami, N.; Taheri-Ledari, R.; Maleki, A. Highly facilitated synthesis of phenyl (tetramethyl) acridinedione pharmaceuticals by a magnetized nanoscale catalytic system, constructed of GO, Fe3O4 and creatine. Diam. Relat. Mater. 2020, 102, 107661.

9. Shi, D.Q.; Ni, S.N.; Shi, J.W.; Dou, G.L.; Li, X.Y.; Wang, X.S. An efficient synthesis of polyhydroacridine derivatives by the threecomponent reaction of aldehydes, amines and dimedone in ionic liquid. J. Heterocycl. Chem. 2008, 45, 653-660.

10. Chavan, P.N.; Pansare, D.N.; Shelke, R.N. Eco-friendly, ultrasound-assisted, and facile synthesis of one-pot multicomponent reaction of acridine-1, $8(2 \mathrm{H}, 5 \mathrm{H})$-diones in an aqueous solvent. J. Chin. Chem. Soc. 2019, 66, 822-828.

11. Javid, A.; Khojastehnezhad, A.; Heravi, M.; Bamoharram, F.F. Silica-supported preyssler nanoparticles catalyzed simple and efficient one-pot synthesis of 1,8-dioxodecahydroacridines in aqueous media. Synth. React. Inorg. Met.-Org. Nano-Met. Chem. 2012, 42, 14-17.

12. Abu-Dief, A.M.; Mohamed, W. $\alpha$-Bi2O3 nanorods: Synthesis, characterization and UV-photocatalytic. Activity. Mater. Res. Express $\mathbf{2 0 1 7}, 4$, 035039.

13. Zeynizadeh, B.; Gilanizadeh, M. Microwave-promoted three-component Hantzsch synthesis of acridinediones under green conditions. Curr. Chem. Lett. 2020, 9, 71-78.

14. Patil, D.; Chandam, D.; Mulik, A.; Patil, P.; Jagadale, S.; Kant, R.; Gupta, V.; Deshmukh, M. Novel Brønsted acidic ionic liquid ([CMIM][CF 3 COO]) prompted multicomponent hantzsch reaction for the eco-friendly synthesis of acridinediones: An efficient and recyclable catalyst. Catal. Lett. 2014, 144, 949-958. 